Research article

urn:1sid:zoobank.org:pub:39894204-DA29-4378-B378-F2F5C10BB345

\title{
Two new species of the genus Terrobittacus Tan \& Hua, 2009 (Mecoptera: Bittacidae) from southwestern China with a key to species
}

\author{
Wei DU ${ }^{1} \&$ Bao-Zhen HUA ${ }^{2, *}$ \\ ${ }^{1,2}$ Key Laboratory of Plant Protection Resources and Pest Management, Ministry of Education, \\ Entomological Museum, Northwest A\&F University, Yangling, Shaanxi 712100, China. \\ ${ }^{*}$ Corresponding author: huabzh@nwafu.edu.cn \\ 1Email: duweiedu@nwafu.edu.cn \\ ${ }^{1}$ urn:Isid:zoobank.org:author:A0626819-271A-40BF-92E8-BCE8D13F2B8C \\ ${ }^{2}$ urn:1sid:zoobank.org:author:C02F1E14-1B20-4B92-BA8F-57937D3D3137
}

\begin{abstract}
Two new species of hangingflies, Terrobittacus rostratus sp. nov. and Terrobittacus angustus sp. nov., are described and illustrated from Yunnan, southwestern China, increasing the species number of Terrobittacus Tan \& Hua, 2009 to six. Terrobittacus rostratus sp. nov. differs from its congeners by wings devoid of markings and epandrial appendages slightly longer than half the length of the gonocoxites. Terrobittacus angustus sp. nov. can be recognized by wing markings along $\mathrm{R}_{5}$ distally. A key to species of the genus is updated to include the two new species.
\end{abstract}

Key words. Hangingflies, taxonomy, biodiversity, Yunnan, China.

Du W. \& Hua B.-Z. 2017. Two new species of the genus Terrobittacus Tan \& Hua, 2009 (Mecoptera: Bittacidae) from southwestern China with a key to species. European Journal of Taxonomy 294: 1-13. https://doi.org/10.5852/ ejt.2017.294

\section{Introduction}

Bittacidae Handlirsch, 1906, a cosmopolitan family of Mecoptera Packard, 1886, is peculiar for the adults having three pairs of raptorial legs, each with a grasping structure formed by the fourth and fifth tarsomeres (Tan \& Hua 2008). They usually use their prehensile tarsi to hang themselves from the edge of leaves or twigs of plants; therefore, they are commonly called hangingflies (Byers 2002). The bittacids are mostly found in moist, shady woodlands and have strict habitat requirements (Setty 1940; Byers \& Thornhill 1983). During mating, the male frequently provides an insect prey as a nuptial gift to the female, and twists his abdomen temporarily up to $180^{\circ}$ to form a belly-to-belly hanging copulation position with the female (Gao \& Hua 2013).

As the second largest family in Mecoptera, Bittacidae comprises 18 extant genera and over 200 described species in the world (Bicha 2011; Byers 2011; Chen et al. 2013). Thirty-five species in three genera (Bittacus Latreille, 1805, Bicaubittacus Tan \& Hua, 2009 and Terrobittacus Tan \& Hua, 2009) have been recorded in China to date (Cheng 1957; Tan \& Hua 2009a, 2009b; Chen et al. 2013; Du et al. 2015). 
The genus Terrobittacus is endemic to China - it is known from the Shaanxi, Henan, Hunan, Guizhou, and Fujian provinces - and has Bittacus implicatus Huang \& Hua in Cai et al., 2006 as its type species. Herein, two undescribed species of Terrobittacus from Yunnan, southwestern China, are described as new to science, thereby increasing the species number of Terrobittacus to six. A key to species of the genus is updated to include the two new species.

\section{Material and methods}

Type specimens were collected from montane areas in Yongde County, Yunnan Province, and are deposited in $75 \%$ ethanol at the Entomological Museum, Northwest A\&F University, China (NWAU).

Specimens were observed under a Nikon SMZ1500 microscope. Photographs were taken with a Nikon D7000 digital camera, and stacked with Zerene stacker (version 1.04) software. For scanning electron microscopy (SEM), the samples were dehydrated in a graded ethanol series, replaced by tertiary butanol, dried in a $\mathrm{CO}_{2}$ critical-point dryer, sputter-coated with gold and examined under a Hitachi S-3400N scanning electron microscope (Hitachi, Tokyo, Japan) at $15 \mathrm{kV}$. The measurements were obtained with a vernier caliper, and are presented as mean $\pm \mathrm{SD}$ (standard deviation).

\section{Abbreviations}

The following abbreviations are used in measurements:

$\mathrm{BL}=$ body length

$\mathrm{FL}=$ forewing length

$\mathrm{FW}=$ forewing width

$\mathrm{HL}=$ hindwing length

$\mathrm{HW}=$ hindwing width

The following abbreviations are used in describing wing venation:
$\mathrm{Av}=$ apical cross-vein between $\mathrm{CuP}$ and $1 \mathrm{~A}$
$\mathrm{CuA}=$ anterior cubitus
$\mathrm{CuP}=$ posterior cubitus
$\mathrm{Cuv}=$ apical cross-vein between $\mathrm{CuA}$ and $\mathrm{CuP}$
$\mathrm{FM}=$ fork of media
FRs $=$ first fork of radial sector
ORs $=$ the origin of radial sector
$\mathrm{Pcv}=$ cross-veins between $\mathrm{R}_{1}$ and $\mathrm{R}_{2}$ behind the pterostigma
$\mathrm{R}_{1} \quad=$ first radius
$\mathrm{Sc}=$ subcosta
$\mathrm{Scv}=$ cross-vein between distal half of Sc and $\mathrm{R}_{1}$

\section{Results}

Class Insecta Linnaeus, 1758

Order Mecoptera Packard, 1886

Family Bittacidae Handlirsch, 1906

Genus Terrobittacus Tan \& Hua, 2009

Terrobittacus Tan \& Hua, 2009b: 2938. Type species: Bittacus implicatus Huang \& Hua in Cai et al., 2006 by original designation. 


\section{Diagnosis}

The genus can be recognized by the following characters: 1) wings with one pterostigmal cross-vein; 2) tarsomere IV with one spine on each side; 3) male epandrial appendages distinctly shorter than half the length of the gonocoxites, except for $T$. rostratus sp. nov. with epandrial appendages slightly longer than half the length of the gonocoxites; aedeagal lobes small and acute; tergum X strongly vestigial dorsally; sex pheromone glands single-lobed; 4) the two halves of the subgenital plate almost fused completely in the female.

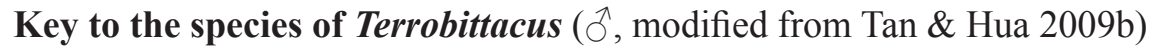

1. Thorax with a distinct pale yellowish streak mesally; wings with cross-veins $r-m$ and $m$ connected at fork of $\mathrm{M}_{1+2}\left(\mathrm{FM}_{1+2}\right)$; cerci longer than epandrial appendages; gonocoxites with one to three pairs of long convergent bristles apically ............................ longisetus Tan \& Hua, 2009

- Thorax without a distinct mesal streak; cross-veins $\mathrm{r}-\mathrm{m}$ and $\mathrm{m}$ connected before $\mathrm{FM}_{1+2}$; cerci shorter than epandrial appendages; gonocoxites without long bristles apically $\ldots \ldots \ldots \ldots \ldots \ldots . . .2$

2. Blackish brown cloudings diffused along most cross-veins forming two noticeable bands or along $R_{5}$ with a brown fleck; proctiger pointed, with its apex rounded $\ldots \ldots \ldots \ldots \ldots \ldots \ldots \ldots \ldots \ldots \ldots \ldots \ldots \ldots$

- No noticeable marked bands along cross-veins; apex of proctiger not rounded ................4

3. Epandrial appendages roughly trapezoid in lateral view

T. echinatus (Hua \& Huang in Hua et al. 2008)

- Epandrial appendages clavate in lateral view T. angustus sp. nov.

4. Proctiger slender, sabre-shaped, curved caudad, acute apically T. xiphicus Tan \& Hua, 2009

- Proctiger relatively thick; apex curved caudoventrally into a hook, like rostrum of a parrot .5

5. Epandrial appendages boot-shaped in lateral view ....................... rostratus $\mathrm{sp}$. nov. - Epandrial appendages triangular in lateral view ...T. implicatus (Huang \& Hua in Cai et al., 2006)

Terrobittacus rostratus sp. nov. urn:1sid:zoobank.org:act:35A77A25-C607-46F1-8E5E-869BFC75BCBD

Figs $1-4,9 \mathrm{C}$

\section{Diagnosis}

The new species differs from its congeners by the following characters: 1 ) wings hyaline without clouded markings; 2) male epandrial appendages boot-shaped in lateral view, upper branch of proctiger broad with two round lateral flanks and a beak-like apex; 3) female subgenital plate black basally, yellowish brown distally, and with a narrow membranous line mesally.

\section{Etymology}

The specific epithet is derived from the Latin 'rostratus' (beak-shaped), referring to the beak-shaped upper branch of the proctiger in the male.

\section{Type material}

\section{Holotype}

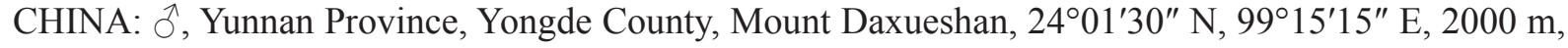
29 Aug. 2015, coll. Ji-Shen Wang (NWAU). 
Paratypes

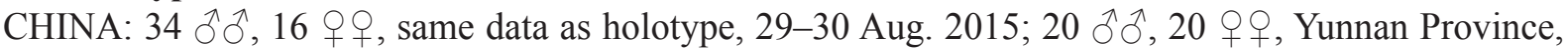

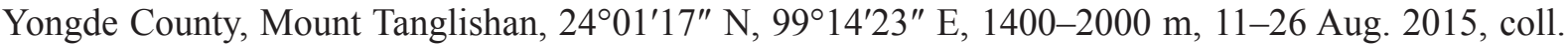
Ji-Shen Wang (NWAU).

\section{Description}

MeAsurements. Male $(n=20): \mathrm{BL}=11.16 \pm 0.94 \mathrm{~mm} ; \mathrm{FL}=15.80 \pm 0.42 \mathrm{~mm}, \mathrm{FW}=3.66 \pm 0.19 \mathrm{~mm}$; $\mathrm{HL}=13.93 \pm 0.39 \mathrm{~mm}, \mathrm{HW}=3.21 \pm 0.13 \mathrm{~mm}$. Female $(n=20): \mathrm{BL}=11.5 \pm 0.84 \mathrm{~mm} ; \mathrm{FL}=15.76 \pm$ $1.16 \mathrm{~mm}, \mathrm{FW}=3.73 \pm 0.14 \mathrm{~mm} ; \mathrm{HL}=13.96 \pm 1.13 \mathrm{~mm}, \mathrm{HW}=3.28 \pm 0.15 \mathrm{~mm}$ (Fig. 1A).

HEAD. Vertex and frons yellowish brown; clypeus lighter than frons; genae pale; labrum yellowish brown, darker basally and laterally; maxillary and labial palps dark brown; fifth segment of maxillary palp slightly longer than fourth (Fig. 1B). Ocellar triangle black; three ocelli almost equal in diameter; median ocellus accompanied with two bristles. Antennae filiform and ciliated; scape and flagellum dark brown, pedicel pale brown; flagellum with distinct segments basally and obscure beyond $13^{\text {th }}$ segment.

Thorax. Pronotum black, with two long setae on anterior margin, and a few setae on posterior margin. Anterior two-thirds of mesonotum black, remaining part and metanotum unevenly brown; meso- and metascutellum each with two long black setae (Fig. 1C). Pleura unevenly pale brown. Legs yellowish brown, except coxae pale brown, femora and tibiae darker apically (Fig. 1A); fourth tarsomere with one spine on each side; hind basitarsus longer than second and third tarsomeres together.
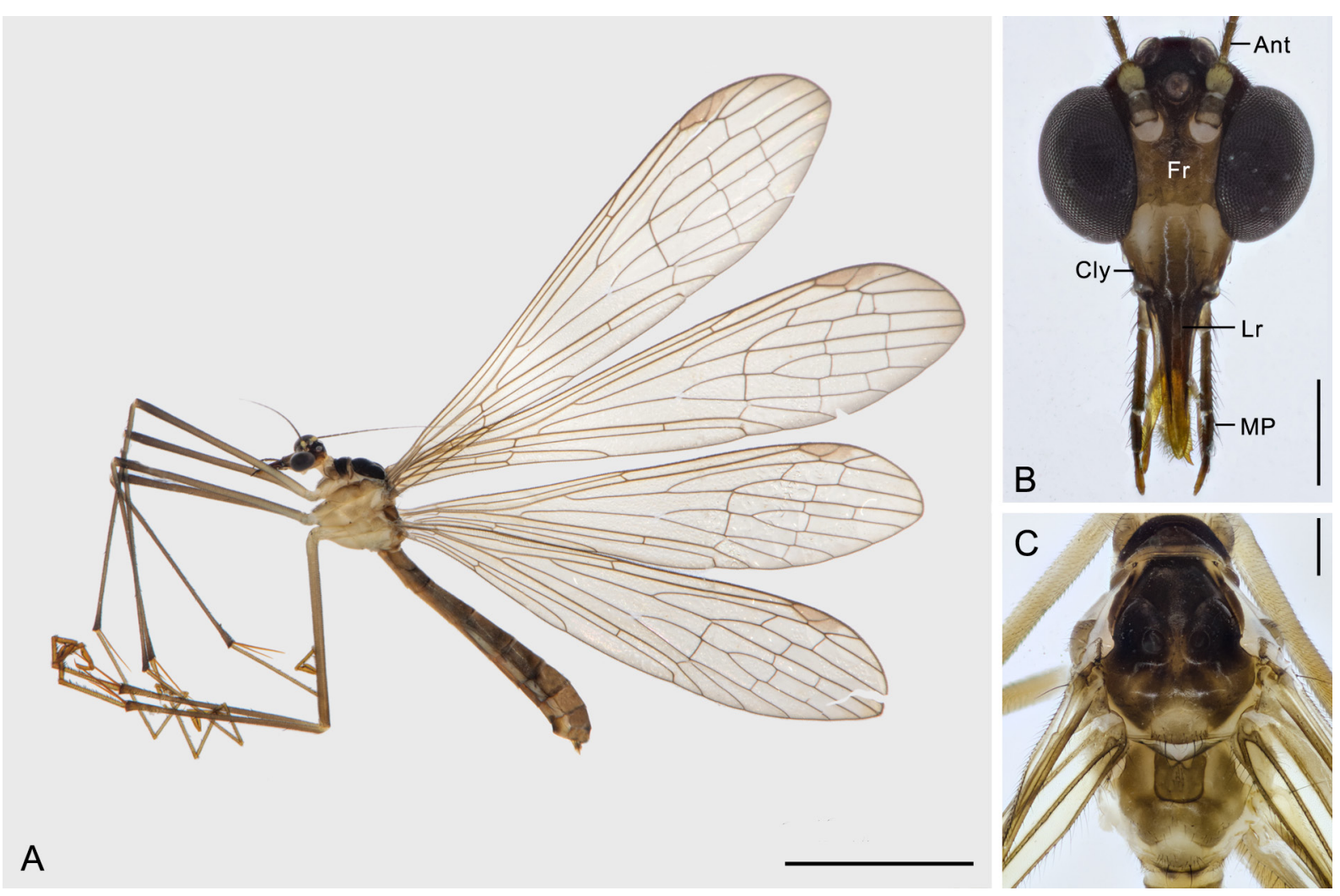

Fig. 1. Terrobittacus rostratus sp. nov. A. , habitus in lateral view. B. Head in frontal view. C. Thorax in dorsal view. Abbreviations: $\mathrm{Ant}=$ antenna; $\mathrm{Cly}=$ clypeus; $\mathrm{Fr}=$ frons; $\mathrm{Lr}=$ labrum; $\mathrm{MP}=$ maxillary palp. Scale bars: $\mathrm{A}=5.0 \mathrm{~mm}$; $\mathrm{B}-\mathrm{C}=0.5 \mathrm{~mm}$. 
Wings. Forewing membrane hyaline and tinged with yellowish brown; pterostigma brown; apical margin slightly infuscate; thyridium at FM conspicuous; two nygmata each in cells $\mathrm{R}_{4+5}$ and $1 \mathrm{R}_{5}$; one Pcv; Sc ending beyond the level of FRs; Cuv near level of FM; CuA ending slightly beyond Sc terminus, $\mathrm{CuP}$ terminating near level of Scv; Av absent, 1A terminating beyond the level of ORs; apical crossveins roughly arranged in three lines. Hindwings similar to forewings, but Sc terminating at level of midpoint between ORs and FRs; 1A coalesced with CuP subbasally; apical cross-veins fewer than those of forewings (Fig. 2).

ABdomen of MALE. Terga II-VIII light brown to dark brown, each with a black narrow antecosta; tergum VIII emarginated on posterior margin. Sterna II-VIII pale to dark brown, sternum IX lighter than sternum VIII. Sex pheromone glands single-lobed, each at intersegmental areas between terga VI-VII and between terga VII-VIII (Fig. 3A). Epandrial appendages (tergum IX) yellowish brown, slightly longer than half the length of gonocoxites, boot-shaped in lateral view, with basal third broad and distal two-thirds narrowed toward rounded apex; inner surface with two patches of small black spines each at apex and dorsal process (Fig. 3B-C), and margin from dorsal process to apex also with sparse spines. Tergum $X$ strongly vestigial dorsally with two slender lateral plates extending to base of lower branch of proctiger. Upper branch of proctiger flat, strongly sclerotized with two broad lateral flanks bearing scattered setae, apex curved caudoventrad into a beak; lower branch of proctiger shorter than upper branch, curved downward and tapering apically (Fig. 3D). Cerci conical, almost one-third as long as gonocoxites (Fig. 3A). Gonocoxites yellowish brown, caudal portion with a pale U-shaped membranous area (Fig. 3E). Gonostyli stout basally, distal portion curved cephalad and tapering toward apex. Aedeagus broad basally, with two aedeagal lobes acute and median penisfilum coiled greatly (Fig. 3A, E).

Abdomen of female. Terga II-IX yellowish brown or unevenly brown, each with a narrow black antecosta. Sterna II-VII yellowish brown, or pale in sterna II-IV and unevenly dark brown in sterna V-VII. Subgenital plate black basally, yellowish brown distally (Fig. 4A), and with a rather narrow membranous line mesally, which is broadened at distal half (Fig. 4B); a pair of acute processes each

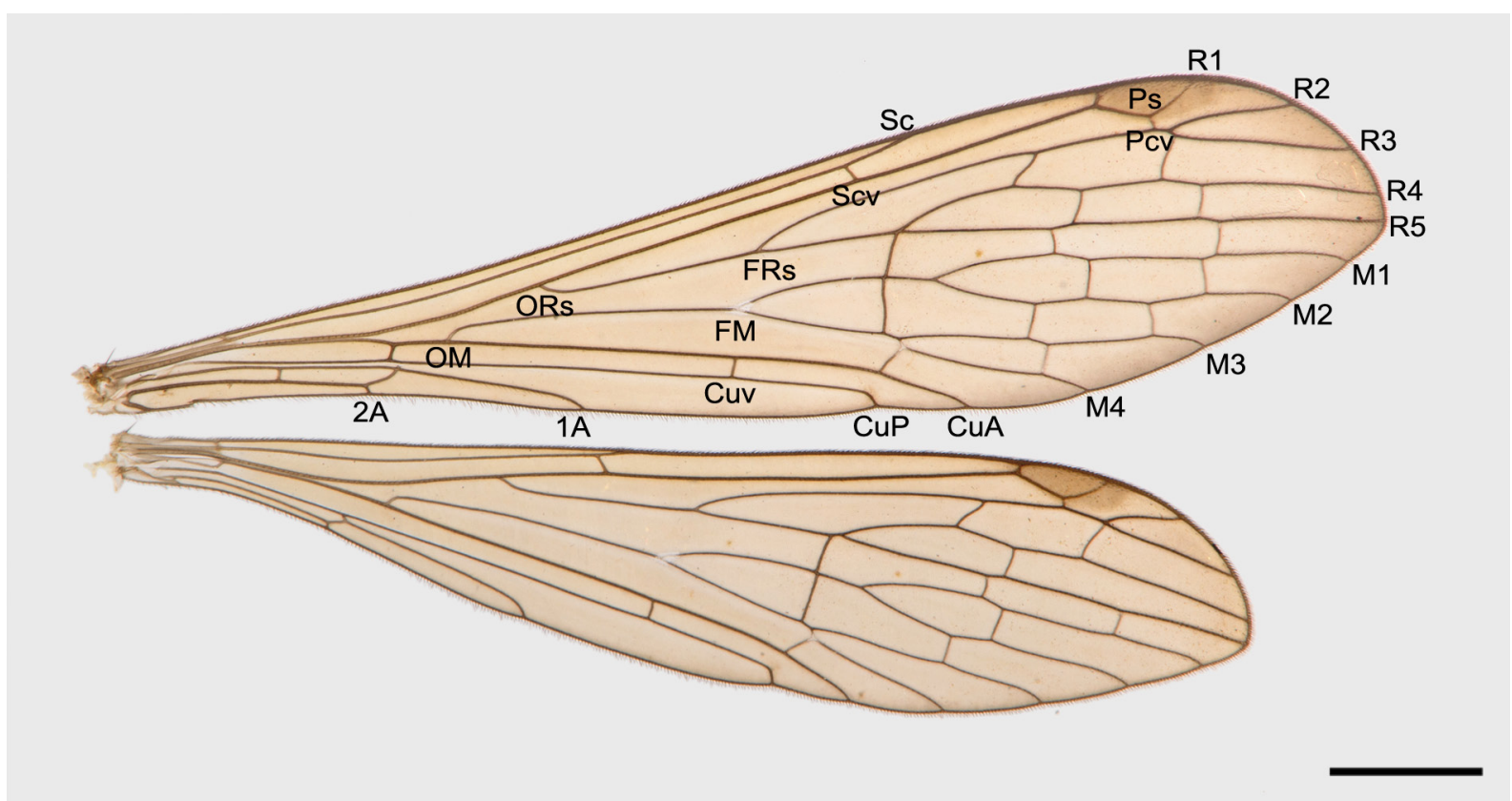

Fig. 2. Right wings of a male specimen of Terrobittacus rostratus sp. nov. Scale bar $=2.0 \mathrm{~mm}$. 

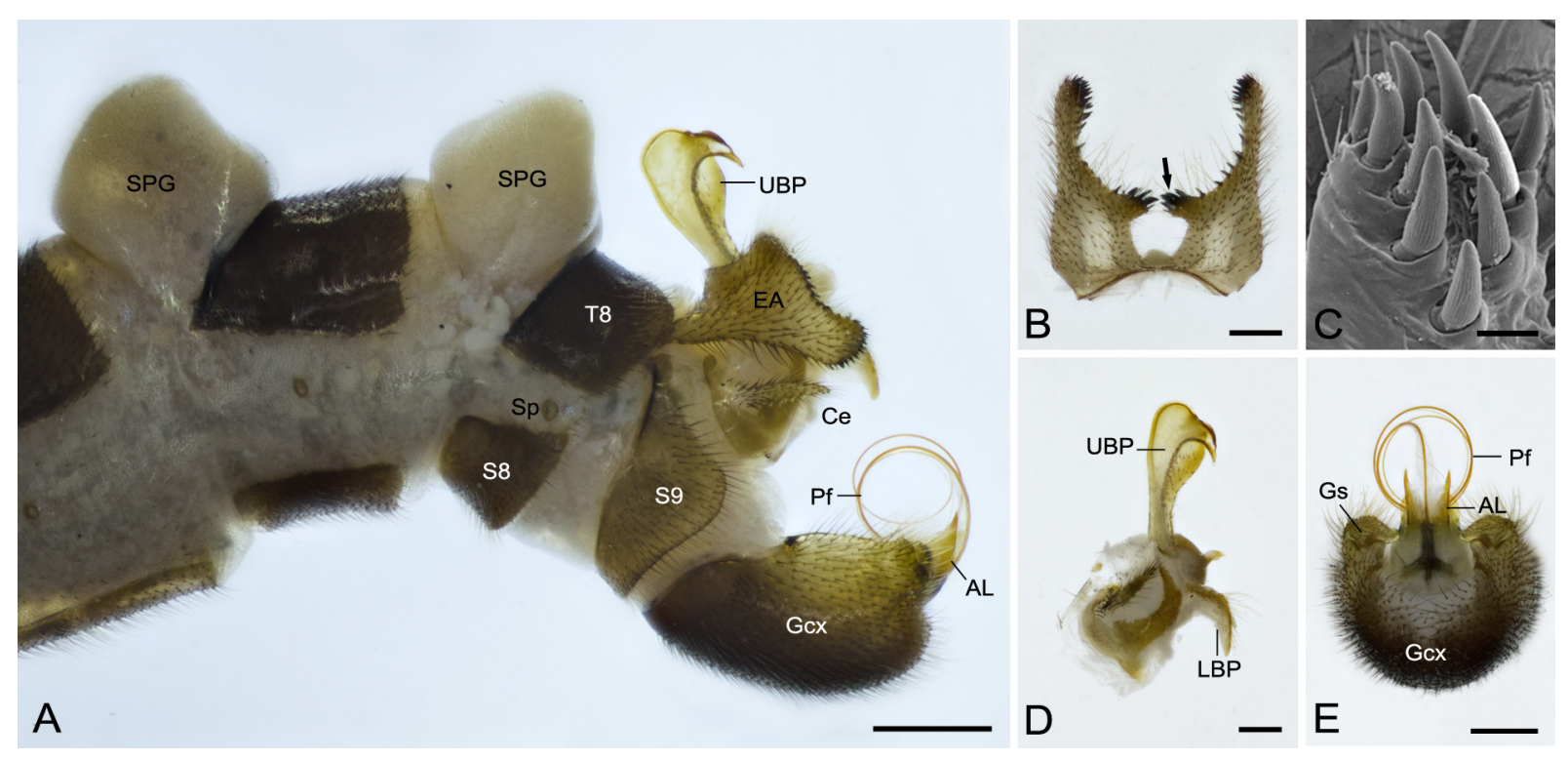

Fig. 3. Male genitalia of Terrobittacus rostratus sp. nov. A. Terminalia in lateral view. B. Epandrial appendages in dorsal view $=$ arrow shows the dorsal process. C. Spines on dorsal process of epandrial appendages $=$ SEM micrograph. D. Abdominal segment $\mathrm{X}$ and proctiger in lateral view. E. Genitalia in caudal view. Abbreviations: $\mathrm{AL}=$ aedeagal lobe; $\mathrm{Ce}=$ cercus; $\mathrm{EA}=$ epandrial appendage; $\mathrm{Gcx}=$ gonocoxite; $\mathrm{Gs}=$ gonostylus; $\mathrm{LBP}=$ lower branch of proctiger; $\mathrm{Pf}=$ penisfilum; $\mathrm{S}=$ sternum; $\mathrm{Sp}=$ spiracle; $\mathrm{SPG}=$ sex pheromone gland; $\mathrm{T}=$ tergum; $\mathrm{UBP}=$ upper branch of proctiger. Scale bars: $\mathrm{A}=$ $0.5 \mathrm{~mm} ; \mathrm{B}, \mathrm{D}-\mathrm{E}=0.2 \mathrm{~mm} ; \mathrm{C}=25 \mu \mathrm{m}$.

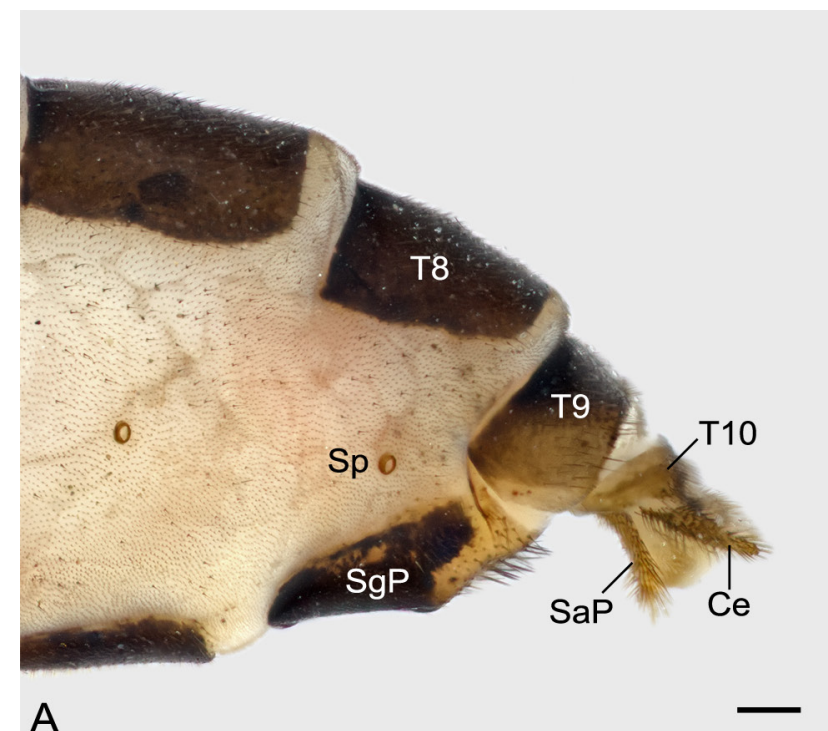

A

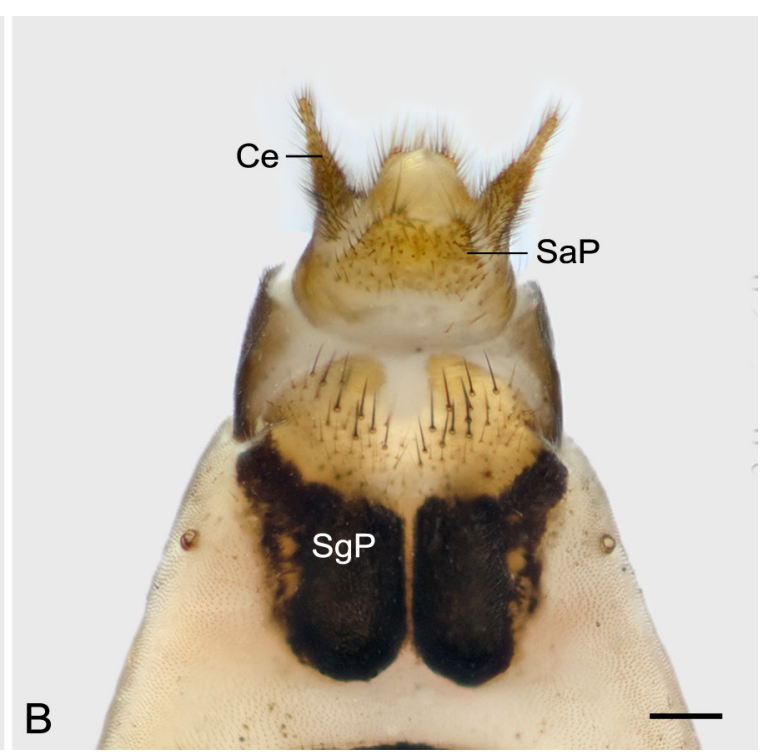

Fig. 4. Female terminalia of Terrobittacus rostratus sp. nov. A. Lateral view. B. Ventral view. Abbreviations: $\mathrm{Ce}=$ cercus; $\mathrm{SaP}=$ subanal plate; $\mathrm{SgP}=$ subgenital plate; $\mathrm{Sp}=$ spiracle; $\mathrm{T}=$ tergum. Scale bars $=0.2 \mathrm{~mm}$. 
projecting from lateral margins distally, and extending to anterior edge of tergum IX; distal portion of subgenital plate with long thick setae directed caudad (Fig. 4A-B). Tergum X yellowish brown, extending ventrad. Supraanal plate and subanal plate truncated apically. Cerci setose, slightly longer than supraanal plate.

\section{Distribution}

Yunnan Province, China.

\section{Remarks}

The new species differs from other species of Terrobittacus in its male epandrial appendages, which is slightly longer than half the length of the gonocoxites.

Terrobittacus rostratus sp. nov. resembles T. longisetus and T. implicatus in general appearance, especially the hook-like proctiger in the male genitalia. However, it can be separated from the latter two species by its boot-shaped epandrial appendages. In addition, wings are devoid of markings in T. rostratus sp. nov., but have clouded markings in the latter two species. Females of T. rostratus sp. nov. can also be differentiated from congeners by the unique coloration of its subgenital plate, which is black basally and yellowish brown distally.

Terrobittacus angustus sp. nov.

urn:lsid:zoobank.org:act:6279AC78-C9AA-4108-A537-F752F9B31318

Figs 5-8, 9D

\section{Diagnosis}

The new species is distinguished from its congeners by the following characters: 1) wings with a clouded brown fleck along $\mathrm{R}_{5}$ distally; 2) male epandrial appendages narrow, with small black spines on inner

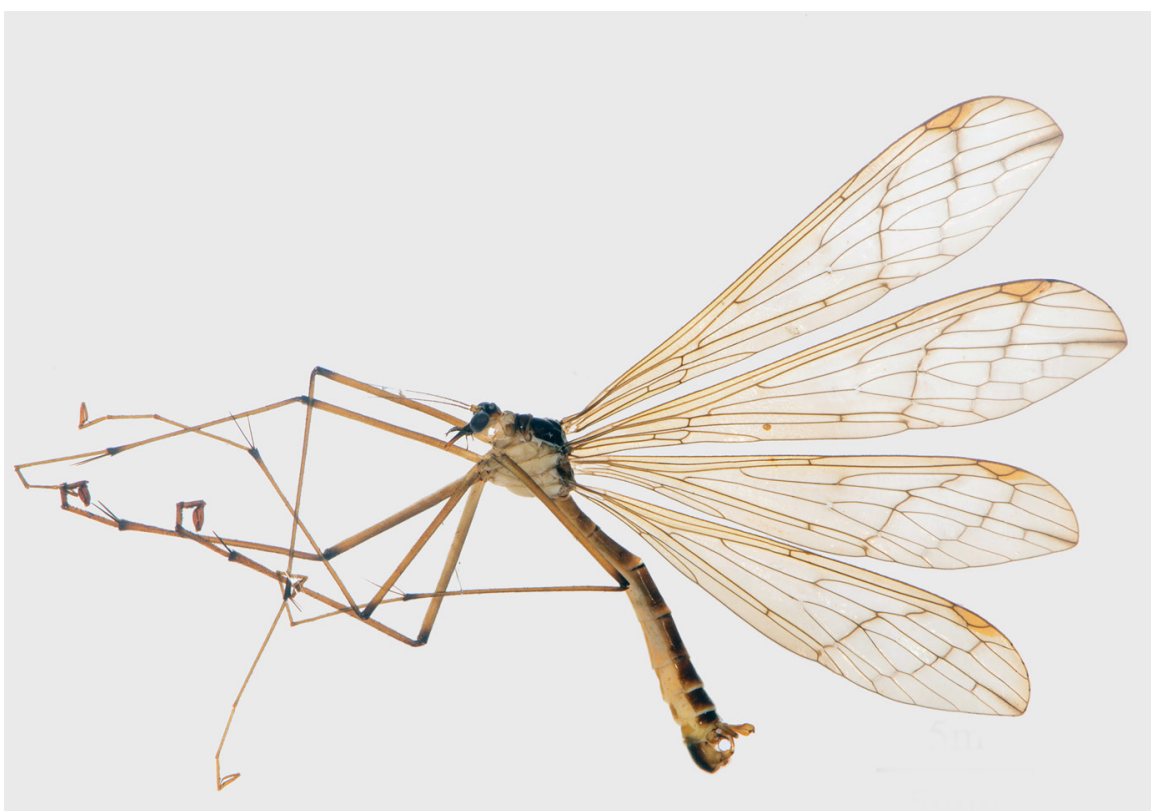

A

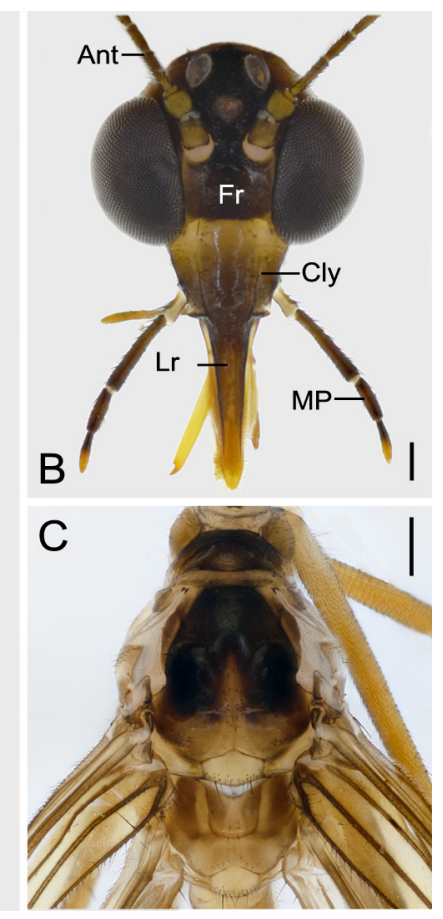

Fig. 5. Terrobittacus angustus sp. nov. A. $\widehat{\partial}$, habitus in lateral view. B. Head in frontal view. C. Thorax in dorsal view. Abbreviations: $\mathrm{Ant}=$ antenna; $\mathrm{Cly}=$ clypeus; $\mathrm{Fr}=$ frons; $\mathrm{Lr}=$ labrum; $\mathrm{MP}=$ maxillary palp. Scale bars: $A=5.0 \mathrm{~mm} ; \mathrm{B}=0.2 \mathrm{~mm} ; \mathrm{C}=0.5 \mathrm{~mm}$. 


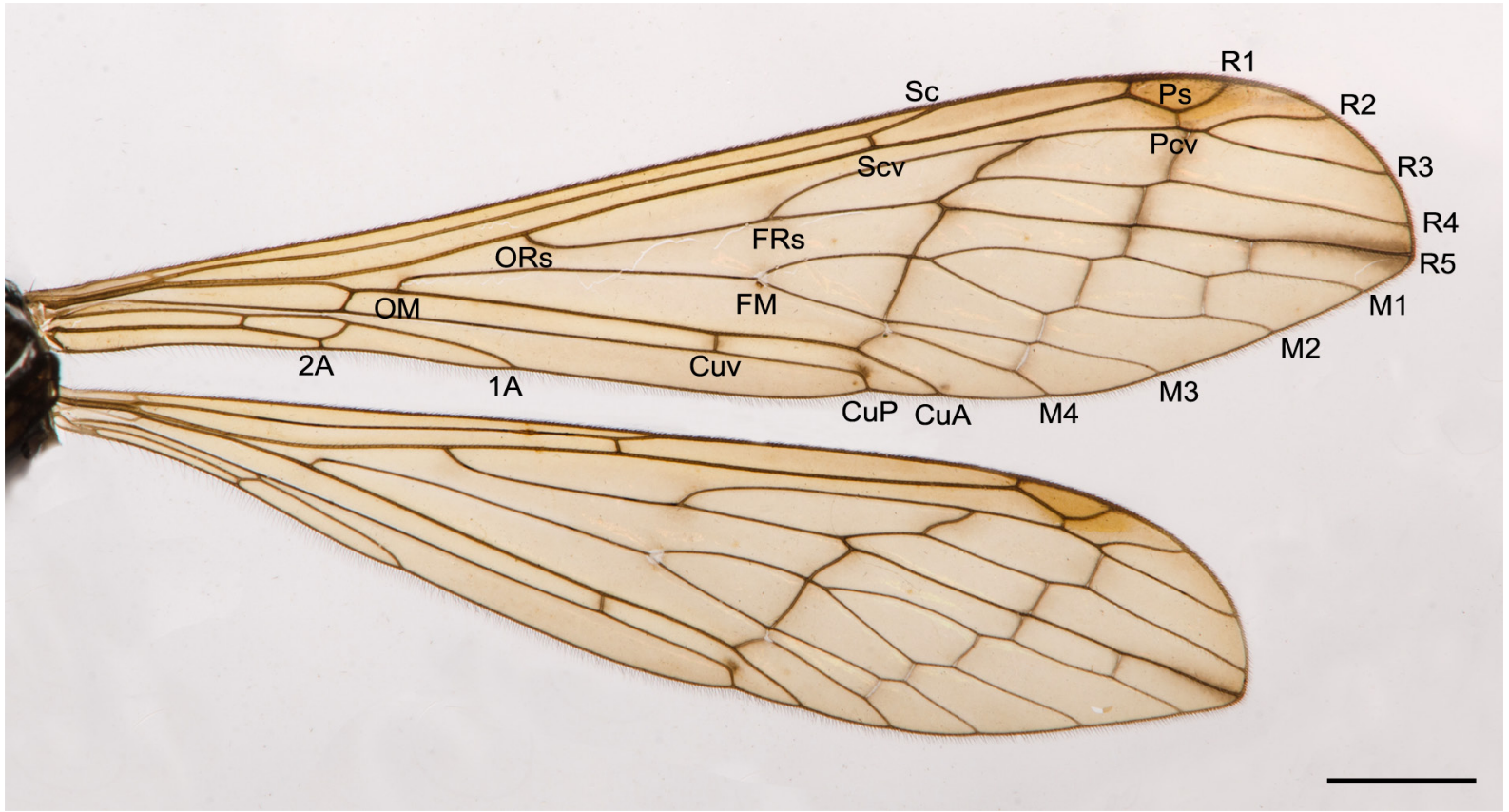

Fig. 6. Right wings of a male specimen of Terrobittacus angustus sp. nov. Scale bar $=2.0 \mathrm{~mm}$.

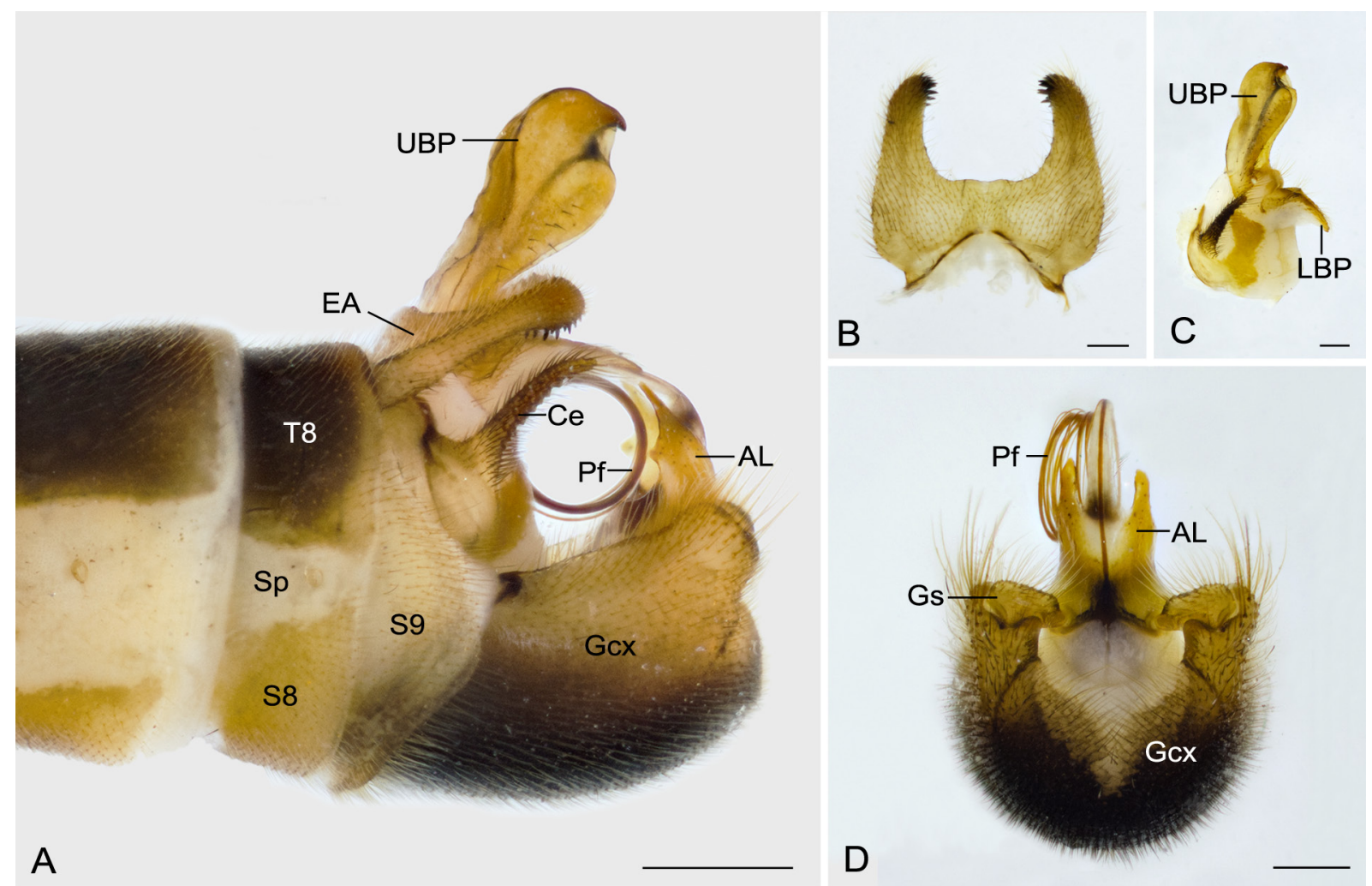

Fig. 7. Male genitalia of Terrobittacus angustus sp. nov. A. Terminalia in lateral view. B. Epandrial appendages in dorsal view. C. Abdominal segment $X$ and proctiger in lateral view. D. Genitalia in caudal view. Abbreviations: $\mathrm{AL}=$ aedeagal lobe; $\mathrm{Ce}=$ cercus; $\mathrm{EA}=$ epandrial appendage; $\mathrm{Gcx}=$ gonocoxite; $\mathrm{Gs}=$ gonostylus; LBP = lower branch of proctiger; $\mathrm{Pf}=$ penisfilum; $\mathrm{S}=$ sternum; $\mathrm{Sp}=$ spiracle; $\mathrm{T}=$ tergum; UBP $=$ upper branch of proctiger. Scale bars: $A=0.5 \mathrm{~mm} ; \mathrm{B}-\mathrm{D}=0.2 \mathrm{~mm}$. 
surface of rounded apex; 3) female subgenital plate with a triangular membranous area basally and deeply cleft distally, two black sclerotized carinae at anterior portion.

\section{Etymology}

The specific epithet is derived from the Latin 'angustus' (narrow), referring to the narrow shape of the epandrial appendages in lateral view.

\section{Type material}

\section{Holotype}

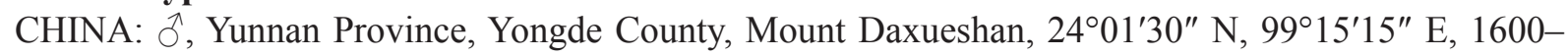
2500 m, 21 Aug. 2015, Ji-Shen Wang leg. (NWAU).

\section{Paratypes}

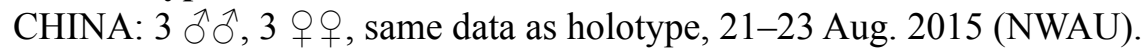

\section{Description}

Measurements. Male $(n=4): \mathrm{BL}=13.86 \pm 0.61 \mathrm{~mm} ; \mathrm{FL}=18.72 \pm 0.34 \mathrm{~mm}, \mathrm{FW}=4.16 \pm 0.13 \mathrm{~mm}$; $\mathrm{HL}=16.61 \pm 0.32 \mathrm{~mm}, \mathrm{HW}=3.60 \pm 0.16 \mathrm{~mm}$. Female $(n=3): \mathrm{BL}=13.37 \pm 0.38 \mathrm{~mm} ; \mathrm{FL}=18.31 \pm$ $0.36 \mathrm{~mm}, \mathrm{FW}=4.19 \pm 0.15 \mathrm{~mm} ; \mathrm{HL}=16.17 \pm 0.49 \mathrm{~mm}, \mathrm{HW}=3.61 \pm 0.12 \mathrm{~mm}$ (Fig. $5 \mathrm{~A}$ ).

HEAD. Vertex yellowish brown; frons dark brown; clypeus unevenly brown; genae pale yellow; labrum yellowish brown, with lateral edges darker; maxillary and labial palps brown; fourth maxillary palpomere slightly longer than fifth (Fig. 5B). Ocellar triangle black, median ocellus accompanied with two bristles and slightly smaller than others in diameter. Antennae filiform and ciliated; scape and flagellum yellowish brown, pedicel yellowish; flagellum ca 17-segmented and indistinctly segmented apically.

THORAx. Pronotum dark brown, with 2-4 long black setae along anterior edge, and few setae along posterior edge. Anterior two-thirds of mesonotum dark brown, the remaining portion and metanotum
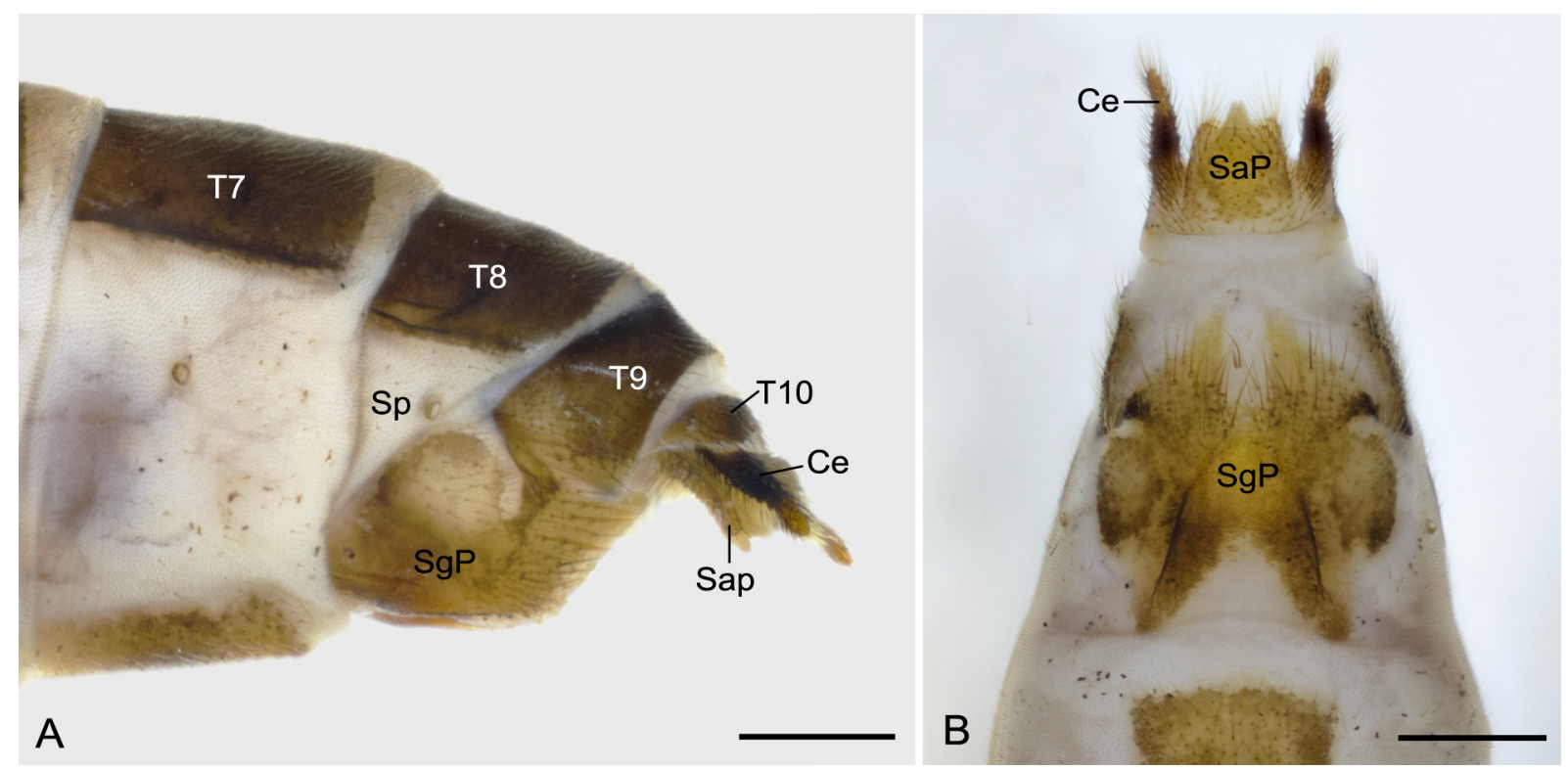

Fig. 8. Female terminalia of Terrobittacus angustus sp. nov. A. Lateral view. B. Ventral view. Abbreviations: $\mathrm{Ce}=$ cercus; $\mathrm{SaP}=$ subanal plate; $\mathrm{SgP}=$ subgenital plate; $\mathrm{Sp}=$ spiracle; $\mathrm{T}=$ tergum. Scale bars $=0.5 \mathrm{~mm}$. 
unevenly yellowish brown; meso- and metascutellum each with two long setae (Fig. 5C). Pleura unevenly pale brown, with scattered setae. Legs yellowish brown except coxae pale brown, femora and tibiae darker apically (Fig. 5A); fourth tarsomere with one spine on each side, hind basitarsus longer than second and third tarsomeres together.

WINGs. Forewing membrane hyaline and tinged with faint yellowish brown, costal margin and apical margin from pterostigma to $\mathrm{R}_{5}$ slightly darkened; pterostigma conspicuous; brown clouded at ORs, FRs, $\mathrm{OM}$ and subdistal CuP, also along apical cross-veins; posterior portion of $\mathrm{R}_{5}$ with a brown clouded fleck broadening toward apex; two thyridia each at $\mathrm{FM}$ and at base of $\mathrm{M}_{4}$; apex of wing almost right-angled and outer margin from $\mathrm{R}_{5}$ to $\mathrm{M}_{3}$ straight; one Pcv; Sc ending beyond level of FRs; CuA ending at level of Sc terminus; CuP ending before level of Scv; Cuv before level of FM; 1A ending at level of ORs, or slightly beyond level of ORs; Av absent; apical cross-veins roughly arranged in two lines; cross-veins between $\mathrm{M}_{2}$ to $\mathrm{M}_{4}$ transparent. Hindwings similar to forewings, but Sc terminated before FRs, $1 \mathrm{~A}$ and $\mathrm{CuP}$ coalesced subbasally (Fig. 6).

Abdomen of MALE. Terga II-VIII yellowish brown to dark brown, each with a black narrow antecosta; tergum VIII slightly emarginated on posterior margin. Sterna II-VI pale yellow, sterna VII-IX yellowish brown. Pleura pale. Epandrial appendages rather narrow, clavate in lateral view, broad basally and narrowing toward rounded apex, and distinctly shorter than half of gonocoxites (Fig. 7A); inner surface with a patch of small black spines apically (Fig. 7B). Tergum X vestigial dorsally, with two lateral plates extending to and surrounding bases of cerci. Upper branch of proctiger strongly sclerotized and with two lateral flanks bearing scattered short setae, its apex slightly curved into a hook; lower branch of proctiger curved downward and shorter than upper branch (Fig. 7C). Cerci dark brown and slightly curved apically, slightly shorter than epandrial appendages. Gonocoxites yellowish brown dorsally and dark brown ventrally, completely joined ventrally and with a V-shaped membranous area posteriorly (Fig. 7A, D); in one specimen, gonocoxites separated by a rather narrow membranous area in ventral aspect. Gonostyli setose and tapering toward apex. Aedeagus with two acute aedeagal lobes each projecting a triangular process from anterior margin mesally; penisfilum greatly elongated, coiled (Fig. 7A, D).

ABdomen of FEMALE. Terga II-IX unevenly dark brown, each with narrow black antecosta. Sterna II-VII pale yellow to yellowish brown. Subgenital plate yellowish brown with pale triangular membranous area basally, and deeply cleft apically; lateral margins oval at basal half, and each projecting a slender process extending to anterior edge of tergum IX distally (Fig. 8A); subgenital plate with long thick setae at posterior portion, and a pair of black carinae at anterior portion (Fig. 8B). Tergum $\mathrm{X}$ yellowish brown and extending ventrad. Supraanal plate and subanal plate truncated apically with long setae, posterior edge of supraanal plate with a small process mesally.

\section{Distribution}

Yunnan Province, China.

\section{Remark}

Terrobittacus angustus sp. nov. is similar to T. rostratus sp. nov. in the general coloration and wing venation, but its wings have clouded markings at forks of major veins, along most apical cross-veins and the distal half of $\mathrm{R}_{5}$ (cf. wings devoid of markings). They can also be readily separated by the external genitalia, for T. angustus sp. nov. has male epandrial appendages clavate in lateral view (cf. epandrial appendages boot-shaped), and female subgenital plate lacking a narrow membranous line mesally (cf. subgenital plate with the membrane in mesal line). 


\section{Discussion}

Hangingflies usually live in the understory of moist, shady woodlands (Fig. 9). During the field survey, we found that hangingflies were extremely vulnerable to aridness and barely survived once they were moved out of their restricted habitats. Previous research has shown that sensilla coeloconica mainly function as hygroreceptors to perceive the humidity of the environment (Altner \& Loftus 1985; Tichy \& Loftus 1996). The antennae of Bittacus sinensis Walker, 1853 possess many more sensilla coeloconica on the flagellomeres than other insects (Hu et al. 2010). This might be the reason why hangingflies are so sensitive to the aridness of the environment. In the natural habitats, hangingflies usually prefer the microhabitats of high humidity, frequently along streams (Fig. 9B).

During mating, the male hangingfly twists his abdomen temporarily up to $180^{\circ}$ and clasps the subgenital plate of the female with his epandrial appendages to ensure the completion of copulation (Mickoleit \& Mickoleit 1978; Gao \& Hua 2013). In male Terrobittacus, however, the epandrial appendages are very short, and have evolved dense stout spines on the inner surface (Fig. 3C). These spines are likely to assist in clasping the female more effectively during copulation.

\section{Acknowledgements}

We are grateful to Ji-Shen Wang for assistance in collecting specimens and taking photographs. We also thank Jiang-Li Tan for comments on the early draft of the manuscript and two anonymous referees for valuable comments on the revision of the manuscript. This research was financially supported by the National Natural Science Foundation of China (Grant no. 30970386).
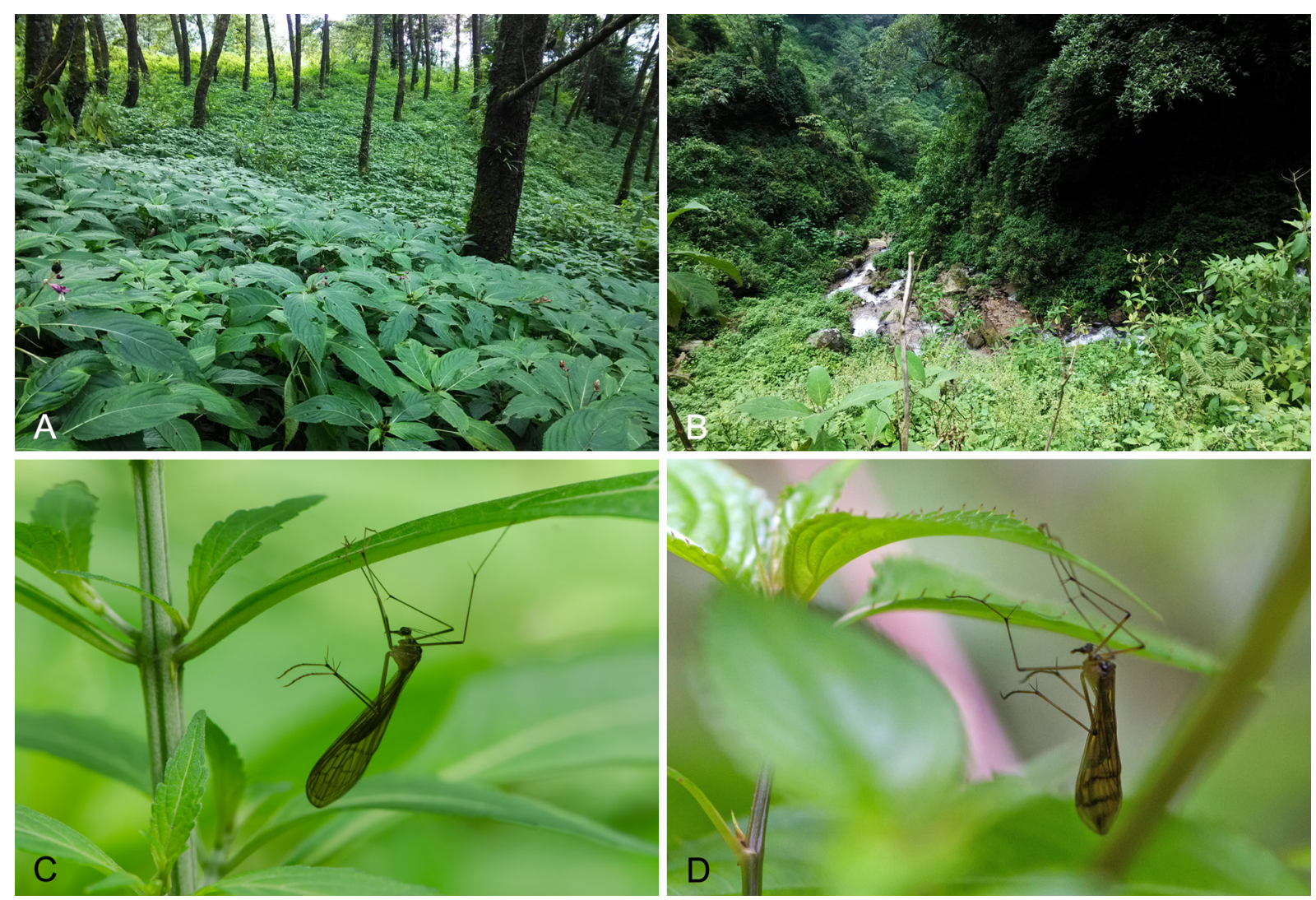

Fig. 9. Habitats of Terrobittacus spp. A-B. Habitats. C. Female specimen of T. rostratus sp. nov. in repose. D. Female specimen of T. angustus sp. nov. in repose. (photos by Ji-Shen Wang) 


\section{References}

Altner H. \& Loftus R. 1985. Ultrastructure and function of insect thermo- and hygroreceptors. Annual Review of Entomology 30: 273-295. https://doi.org/10.1146/annurev.ento.30.1.273

Bicha W.J. 2011. A review of the hangingflies (Mecoptera: Bittacidae) of South Asia with the description of a new species of Bittacus from Nepal. Zootaxa 3032: 60-64. Available from http://www.mapress. com/zootaxa/2011/f/z03032p064f.pdf [accessed 1 Mar. 2017]

Byers G.W. 2002. Scorpionflies, hangingflies, and other Mecoptera. The Kansas School Naturalist 48 (1): 3-15. Available from http://www.emporia.edu/ksn/v48n1-may2002/ [accessed 1 Mar. 2017].

Byers G.W. 2011. Additions to the Mecoptera of Mexico. Journal of the Kansas Entomological Society 84 (1): 1-11. https://doi.org/10.2317/jkes080923.1

Byers G.W. \& Thornhill R. 1983. Biology of the Mecoptera. Annual Review of Entomology 28 (1): 203-228. https://doi.org/10.1146/annurev.en.28.010183.001223

Cai L.-J., Huang P.-Y. \& Hua B.-Z. 2006. Two new Chinese Bittacus Latreille (Mecoptera: Bittacidae) from Michangshan Mountains. Entomotaxanomia 28 (2): 127-130. Available from http://en.cnki.com. cn/Article en/CJFDTotal-KCFL200602009.htm [accessed 1 Mar. 2017]

Chen J., Tan J.-L. \& Hua B.-Z. 2013. Review of the Chinese Bittacus (Mecoptera: Bittacidae) with descriptions of three new species. Journal of Natural History 47 (21-22): 1463-1480. https://doi.org $\underline{10.1080 / 00222933.2012 .763065}$

Cheng F.Y. 1957. Revision of the Chinese Mecoptera. Bulletin of the Museum of Comparative Zoology 116: $1-118$.

Du W., Chen J. \& Hua B.-Z. 2015. Discovery of Bittacus ussuriensis Plutenko (Mecoptera: Bittacidae) from China. Entomotaxonomia 37 (4): 268-272. Available from http://www.cnki.com.cn/Article/ CJFDTOTAL-KCFL201504006.htm [accessed 6 Mar. 2017]

Gao Q.-H. \& Hua B.-Z. 2013. Co-evolution of the mating position and male genitalia in insects: a case study of a hangingfly. PLOS ONE 8 (12): e80651. https://doi.org/10.1371/journal.pone.0080651

Hu X.-W., Liu R.-Z., Liu S.-Y. \& Hua B.-Z. 2010. Comparative ultramorphology of the antennal sensilla between Panorpidae and Bittacidae (Mecoptera). Acta Zootaxonomica Sinica 35 (4): 790-798. Available from http://www.cnki.com.cn/Article/CJFDTOTAL-DWFL201004017.htm [in Chinese, accessed 1 Mar. 2017]

Hua B.-Z., Tan J.-L. \& Huang, P.-Y. 2008. Two new species of the genus Bittacus (Mecoptera: Bittacidae) from China. Zootaxa 1749: 62-68. Available from http://mapress.com/zootaxa/2008/f/z01749p068f.pdf [accessed 1 Mar. 2017]

Mickoleit G. \& Mickoleit E. 1978. Zum Kopulationsverhalten des Mückenhaftes Bittacus italicus (Mecoptera: Bittacidae). Entomologia Generalis 5 (1): 1-15.

Setty L.R. 1940. Biology and morphology of some North American Bittacidae (Order Mecoptera). American Midland Naturalist 23 (2): 257-353. https://doi.org/10.2307/2420667

Tan J.-L. \& Hua B.-Z. 2008. Structure of raptorial legs in Bittacus (Mecoptera: Bittacidae). Acta Entomologica Sinica 51 (7): 745-752. [In Chinese] https://doi.org/10.3321/j.issn:0454-6296.2008.07.011

Tan J.-L. \& Hua B.-Z. 2009a. Bicaubittacus, a new genus of the Oriental Bittacidae (Mecoptera) with descriptions of two new species. Zootaxa 2221: 27-40. Available from http://www.mapress.com/ zootaxa/2009/f/z02221p040f.pdf [accessed 1 Mar. 2017] 
Tan J.-L. \& Hua B.-Z. 2009b. Terrobittacus, a new genus of the Chinese Bittacidae (Mecoptera) with descriptions of two new species. Journal of Natural History 43 (45-48): 2937-2954. https://doi. org $/ 10.1080 / 00222930903359628$

Tichy H. \& Loftus R. 1996. Hygroreceptors in insects and a spider: humidity transduction models. Naturwissenschaften 83: 255-263. https://doi.org/10.1007/bf01149598

Manuscript received: 4 April 2016

Manuscript accepted: 8 June 2016

Published on: 8 March 2017

Topic editor: Gavin Broad

Desk editor: Kristiaan Hoedemakers

Printed versions of all papers are also deposited in the libraries of the institutes that are members of the EJT consortium: Muséum national d'Histoire naturelle, Paris, France; Botanic Garden Meise, Belgium; Royal Museum for Central Africa, Tervuren, Belgium; Natural History Museum, London, United Kingdom; Royal Belgian Institute of Natural Sciences, Brussels, Belgium; Natural History Museum of Denmark, Copenhagen, Denmark; Naturalis Biodiversity Center, Leiden, the Netherlands. 